\title{
Technical assistance to organizations in Guinea seeking to reduce female genital cutting
}

Nafissatou J. Diop

Population Council

Follow this and additional works at: https://knowledgecommons.popcouncil.org/departments_sbsr-rh

Part of the Demography, Population, and Ecology Commons, Family, Life Course, and Society Commons, Gender and Sexuality Commons, International Public Health Commons, Maternal and Child Health Commons, Sociology of Culture Commons, and the Women's Health Commons How does access to this work benefit you? Let us know!

\section{Recommended Citation}

Diop, Nafissatou J. 2006. "Technical assistance to organizations in Guinea seeking to reduce female genital cutting," FRONTIERS Final Report. Washington, DC: Population Council. 


\section{Technical Assistance to Organizations in Guinea Seeking to Reduce Female Genital Cutting}

Nafissatou J. Diop

Population Council, Senegal

October 2006

This study was funded by the U.S. AGENCY FOR INTERNATIONAL DEVELOPMENT (USAID) under the terms of the Cooperative Agreement Number HRN-A-00-98-00012-00 and Population Council In-house project number 5804-53080. The opinions expressed herein are those of the author and do not necessarily reflect the views of USAID. 


\section{TABLE OF CONTENTS}

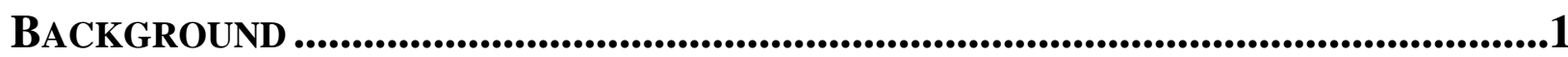

OBJECTIVES Of THE TECHNICAL ASSISTANCE ................................................................1

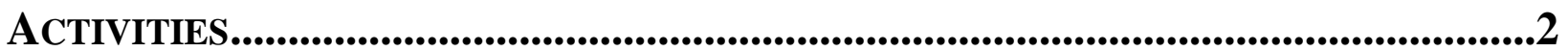

1. Setting up a working group and developing a plan of action ......................................... 2

2. Improving effectiveness of anti-FGC strategies ...................................................... 2

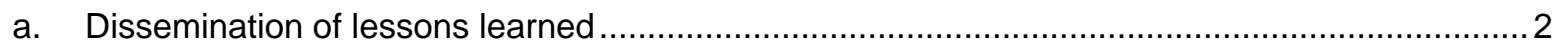

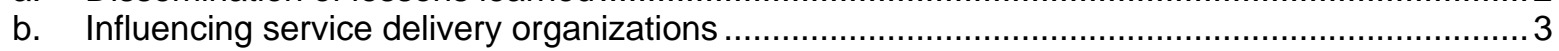

3. Assisting WHO to address medicalization of FGC ...................................................... 3

a. Drawing upon experiences from other FRONTIERS' projects ................................................ 4

b. Developing a research summary booklet to guide implementers........................................ 4

c. Development of tools for assessing the functional capacity of regions to address FGC .............5

d. Technical assistance in data analysis and report preparation................................................. 5

e. Dissemination of results, development of plan of action, and establishment of local

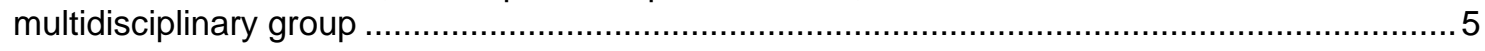

4. Assisting CPTAFE to re-orientate its approach................................................................ 6

5. Assisting TOSTAN to implement its Urban project....................................................... 6

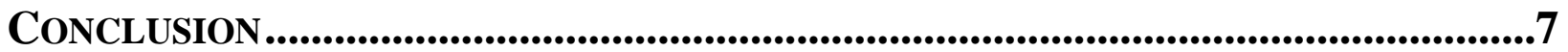



AbBreviations
CNLPE Comité National de Lutte contre la Pratique de l’Excision- Burkina Faso
CPTAFE Comité de Lutte contre les Pratiques Traditionnelles portant Atteinte aux Femmes
$\mathrm{CRDH} \quad$ Centre de Recherche pour le Développement Humain
FGC Female Genital Cutting
GTZ Gesellschaft Fur Technische Zusammenarbeit
IEC Information Education Communication
MNG Multidisciplinary National Group
MLG Multidisciplinary Local Group
M\&E Monitoring and Evaluation
$\mathrm{MOH} \quad$ Ministry of Health
OR Operations Research
TA Technical Assistance
UNICEF United Nations Children's Fund
UNFPA United Nations Fund for Population Activities
USAID United States Agency for International Development
WHO World Health Organization 


\section{BACKGROUND}

USAID's Special Initiative on FGC and its Africa Bureau have supported the Population Council's FRONTIERS and Africa Operations Research Programs for more than ten years, enabling it to sustain an important role in promoting evidence-based strategies for abandoning Female Genital Cutting (FGC) in sub-Saharan Africa. In Mali for example, the Council evaluated strategies for 'converting' excisors and for training health providers to promote FGC abandonment messages during consultations. The results of the first study led to a general abandonment of the strategy of converting excisors in Mali and other countries due to its lack of effectiveness.

The second study led to the Ministry of Health $(\mathrm{MOH})$ issuing a policy directive forbidding staff from carrying out FGC, and to the initiation of an effort, supported by the PRIME II Project, to scale-up training of health providers in FGC education across the country. Several qualitative studies have been undertaken in Burkina Faso to better understand communities' perceptions and attitudes towards FGC, the results of which contributed to a national campaign against the practice. Findings from a comparative study in clinics in Mali and Burkina Faso to observe and measure associations between the type of FGC and negative health outcomes among women attending Reproductive Health (RH) services were published in an international journal. Most recently, FRONTIERS, in collaboration with GTZ, has undertaken an evaluation of the TOSTAN program in Senegal and its replication in Burkina Faso.

FRONTIERS has also implemented several studies in Eastern Africa (Kenya, Sudan, Ethiopia) and in Egypt, including the documentation and evaluation of alternative strategies for encouraging abandonment of the practice, and studies on the medicalization of FGC. FRONTIERS has also supported the creation of the INTACT-network, which links individuals and institutions interested in improving FGC research methodology.

As a result of this range of experiences, the USAID Special Initiative on FGC has supported FRONTIERS to provide technical assistance to organizations working in Guinea, where FGC is highly prevalent. With this funding, FRONTIERS provided technical assistance to WHO's Africa Bureau to implement a project that addressed medicalization of FGC, and supported TOSTAN to replicate its program in Guinea. The project addressed USAID/Guinea's SO2 on reducing Female Genital Cutting.

\section{Objectives of the Technical Assistance}

1. To improve the effectiveness of strategies to abandon FGC in Guinea, through sharing lessons learned from successful FGC strategies undertaken elsewhere.

2. To assist WHO to develop and implement a project to reduce FGC medicalization by health providers through:

i. Sharing lessons learned from studies undertaken in Mali and Kenya;

ii. Developing tools for monitoring and evaluating the project. 
3. To build the capacity of Guinean organizations to appropriately monitor and evaluate their FGC-related activities.

4. To enable the Comité de Lutte contre les Pratiques Traditionnelles portant Atteinte aux Femmes (CPTAFE) to re-orientate its activities towards a comprehensive community approach by utilizing lessons learned from OR.

\section{ACTIVITIES}

\section{Setting up a working group and developing a plan of action}

WHO and FRONTIERS undertook a joint mission to Guinea on February 9-13, 2004 to better understand the potential partners in Guinea, and to develop plans of action that would be complementary and achieve synergy. A two-day meeting was organized with 13 of the main institutions involved in FGC activities in Guinea (see box), as well as the USAID Mission. Each institution presented its current activities and WHO presented an overview of its proposed project on de-medicalization. The participants then contributed ideas to the development of specific activities that should be included in the medicalization project, leading to an action plan for the project, including indicators for monitoring and evaluation (see Annex).

FRONTIERS took a lead role in ensuring that

\begin{tabular}{|l|}
\hline \multicolumn{1}{|c|}{ Participating Institutions } \\
Association of Midwifes \\
Association of Women against AIDS \\
CPTAFE \\
GTZ \\
Ministry of Health \\
Ministry of Social Affairs \\
Ministry of Education \\
Ministry of Technical Training \\
Network of Parliamentarians in Population Issues \\
Peace Corps \\
TOSTAN \\
UNFPA \\
UNICEF \\
\hline
\end{tabular}
lessons learned from past projects with health providers were reflected in the planned activities. Technical assistance was given for the design of the project, as well as identifying the appropriate indicators for monitoring and evaluation, while WHO was responsible for implementing the project with its partners (MOH, CPTAFE, Midwives Association). The participating institutions were organized in a Multi-disciplinary National Group (MNG), whose scope of work was to develop, coordinate and manage all FGC interventions. The terms of reference of the MNG were discussed and set out at the end of the meeting.

\section{Improving effectiveness of anti-FGC strategies}

\section{a. Dissemination of lessons learned}

The first activity under the plan of action was to disseminate the lessons learned from OR and field experiences. FRONTIERS organized a two-day seminar in the capital city, Conakry, for an audience of 80 participants from both the central and regional levels. The participants were drawn from the government, professional associations, donor organizations, and NGOs. The directors of Health and of Social Affairs from all the regions were present. 
Representatives of the Ministry of Social Affairs, the Ministry of Health and WHO addressed the meeting, highlighting the importance of using lessons learned from research to improve programs in the country. FRONTIERS made a presentation on the lessons learned from seven years of OR in Africa (see Annex). The WHO situation analysis of anti-FGC programs in Guinea was also presented. This analysis had been recommended by the WHO Regional Office in Brazzaville, following the dissemination of the regional strategy for accelerating the elimination of FGM. The evaluation showed that very little had been done to eliminate FGC in Guinea, and that policy development and programs needed to be addressed in a more effective and efficient way. GTZ's Supra Regional Project on FGM also presented lessons learned from its work in Guinea and Burkina Faso.

Small working groups were then organized, by region, to discuss the information presented and identify what each region could do to improve their programs. The results of these brainstorming sessions were presented in a plenary session. Each region's presentation heavily criticized the FGC interventions conducted in Guinea, especially those targeting traditional excisors and offered new proposals. Two smaller meetings were also organized, one with the $\mathrm{MOH}$ and one with the Ministry of Social Affairs, to discuss the implications of the lessons learned for their programs.

\section{b. Influencing service delivery organizations}

After the workshop, targeted groups were followed up, including CPTAFE, the Ministries of Health and Social Affairs, the Association of Midwives, and donor organizations. Two donor organizations, UNICEF and UNFPA, were particularly interested in the results presented at the workshop. Consequently, UNICEF decided not to fund any more programs targeting the conversion of excisors, and instead decided to provide more support to the holistic approach implemented by TOSTAN in Guinea. A follow-up meeting with the Ministry of Social Affairs, CPTAFE and TOSTAN discussed the interventions that would be conducted in Guinea. UNFPA was interested in the lessons learned from research on health providers; as a result, UNFPA decided to support the $\mathrm{MOH}$ to train health providers in anti-FGC activities, and to get them more involved in discouraging medicalization.

\section{Assisting WHO to address medicalization of FGC}

WHO/AFRO is testing the introduction of its FGC curriculum, "Integrating the Prevention and the Management of the Health Complications into the Nursing and Midwifery Curricula: A Teacher's Guide,” in Guinea, because the country has a high prevalence of FGC and a high proportion of cutting (30\%) done by health providers in urban areas. The objectives of the project are to reinforce the skills of the medical staff and to reduce the level of cutting by health professionals through:

- Increasing awareness of the risks of FGC among health professionals, leaders, and managers;

- Training health providers;

- Integrating the curricula into medical schools for nurses and midwives. 
FRONTIERS' technical assistance covered the following activities:

- Supporting the development of a plan of action that built upon lessons learned from experiences documented with health providers in Mali and Kenya;

- Gathering summaries, reports and other documentation from projects concerning medicalization and the role of health care providers in Kenya and Mali (and elsewhere) to create a package of background materials for use by WHO and other organizations in Guinea;

- Developing a research summary on the practice of FGC in Guinea, and developing advocacy arguments to counter the justification of FGC by Guinean communities;

- Developing tools for assessing the functional capacity facilities in the pilot region;

- Providing TA for the analysis and reporting of the functional capacity assessment of the pilot region;

- Participating in the establishment and building of skills of the national and local technical committees in the pilot zone;

- Providing support for the evaluation of the project.

\section{a. Drawing upon experiences from other FRONTIERS' projects}

To support the design of WHO's project, FRONTIERS provided the lessons learned from Mali and the tools used, which included a flip chart used during group health talks and individual counseling. Attention was drawn to the strong link that needs to be made with community activities in order to establish a bridge between the health system, the provider and the community worker. FRONTIERS also shared the 'Letter of Decree' issued by the Ministry of Health in Mali at the end of the OR study which forbade the practice of FGC in health facilities or by health providers, as well as the letter issued by the Ministry of Women's Affairs to request support from the $\mathrm{MOH}$ for their decentralized services. In addition, reports, tools and questionnaires developed by FRONTIERS in Kenya for the study on medicalization of FGC among the Abagusii, and the curricula and materials used by the CNLPE in Burkina Faso, developed with assistance from FRONTIERS, were given to the Guinea MOH and WHO to support implementation of the pilot project.

\section{b. Developing a research summary booklet to guide implementers}

FRONTIERS developed a research summary drawing from several quantitative and qualitative studies undertaken in Guinea. Program managers, health providers and social workers used this user-friendly booklet, containing 10 pages of key messages, to counter common arguments made by communities and health providers in support of FGC. The arguments, ranging from health, human rights, sexuality, religion, and hygiene, to culture and socio-economic reasons, are presented in a simple easily understood manner (the booklet is presented in the Annex). The booklet also describes the FGC situation in Guinea and the rationale for the practice. Fivehundred copies were produced and provided to the $\mathrm{MOH}$ and $\mathrm{WHO}$ for distribution in all regions of Guinea. 


\section{Development of tools for assessing the functional capacity of regions to address FGC}

To choose the pilot area for the study, the following criteria were used: existence of a public medical school that trained doctors, midwives and nurses; interest and commitment of the regional medical chief in FGC; presence of a CPTAFE office; GTZ actively working at the community level. Based on these criteria, the MOH chose the Kindia Region.

To assess the functional capacity of the region to implement the project, five instruments were developed and submitted to the Multidisciplinary National Group (MNG) for approval:

- Questionnaire for a census of all health facilities in the Kindia Region;

- Checklist for taking an inventory at each health facility;

- Questionnaire for interviewing health providers;

- Checklist for taking an inventory at each Ministry of Social Affairs facility;

- Questionnaire for assessing community based organizations working in Kindia.

FRONTIERS staff trained the MNG to use each of these instruments and provided a guide for the efficient use of these questionnaires, which included target groups, sampling guidance, and terms of reference (See Annex). Two staff from the MNG conducted the assessment with technical assistance from a FRONTIERS consultant in Guinea.

\section{d. Technical assistance in data analysis and report preparation}

Based on the data it collected, the MNG prepared a draft report document and presented it during a meeting. At the MNG's request, FRONTIERS provided technical assistance to review and revise the analysis and redraft the report; one hundred copies were then produced for distribution by the MOH and WHO (see Annex).

\section{e. Dissemination of results, development of plan of action, and establishment of local multidisciplinary group}

On $9^{\text {th }}-11^{\text {th }}$ October 2005, the MOH organized a workshop in Kindia to launch the project formally. Thirty-eight government representatives attended, including the regional Medical Chief, regional Social Affairs representative, and representatives from the public medical school, Peace Corps, local NGOs, and service providers. FRONTIERS presented and distributed the research summary booklet ${ }^{1}$, and the $\mathrm{MOH}$ presented the results of the functional capacity assessment, as well as the objectives of the project. Participants then developed a detailed project implementation plan (see Annex). At the end of the workshop, a multidisciplinary group that would be responsible for implementation of the project was established.

1 In addition, five OR summaries and two final reports on lessons learned by FRONTIERS were distributed. 


\section{Assisting CPTAFE to re-orientate its approach}

CPTAFE is the longest serving and most important NGO working on activities against FGC in Guinea. Its director is also the Vice President of the Inter-African Committee (IAC). CPTAFE has a decentralized structure, with representation in each region of Guinea. CPTAFE, in collaboration with the Ministry of Social Affairs, implements IEC activities targeting the general population, and also has a large-scale activity that seeks to 'convert' traditional excisors away from the practice. Because these strategies have been demonstrated to be largely ineffective through research studies undertaken in several countries (e.g. Mali, Egypt), CPTAFE was encouraged to consider an evidence-based approach to address the issue of FGC.

The USAID Mission, which was about to issue a new contract to CPTAFE, requested that Council staff review the CPTAFE proposal and provide advice on its technical content. FRONTIERS reviewed and revised the logical framework, and working meetings were held with the CPTAFE director and staff to discuss the recommended changes. FRONTIERS strongly discouraged activities to 'reconvert' excisors, and recommended instead that CPTAFE supported wider dissemination of the national law banning FGC and worked with the media to support its implementation. It was also recommended that CPTAFE become more engaged at the policy level, by using their influence to encourage implementation of the law, to lobby the MOH to pass regulations to forbid the practice by health providers, and to develop and disseminate information about the law through other partners, media spots and IEC materials.

FRONTIERS also suggested to CPTAFE some activities that could be implemented for reaching youth; "Women of Norway" and FOKKUS have now funded this project. In addition, a form was developed for use in documenting the project implementation process for use by CPTAFE staff (see Annex).

\section{Assisting TOSTAN to implement its Urban project}

The Senegalese NGO, TOSTAN, which has successfully implemented community development projects that encourage abandonment of FGC, is implementing a formative research project to gather data on sociological factors determining FGC practices in urban areas in Guinea. The findings will guide project implementers on which strategies to use for agent-based community development programs in urban areas of Guinea. The project is supported by USAID/Guinea and is being implemented in three cities - Conakry, Labé, and Faranah. The Centre de Recherche pour le Développement Humain (CRDH) was chosen by TOSTAN to conduct the survey, and TOSTAN requested FRONTIERS to assist in the development of the study tools and to guide implementation of the research. FRONTIERS TA covered the following:

- Design of the qualitative methodology, review of the objectives, suggestions for the sampling (see Annex);

- Development of guides for in-depth interviews and for focus group discussions. These guides enable collection of data on the socio-cultural context - social organization, links between families in the city and in the villages, the process of marriage, FGC, decision 
making processes, and identification of persons, institutions and mechanisms that will be needed to implement a community program;

- Identification of personnel, in Senegal and Guinea, to work with CDRH in conducting the research study. Two individuals in Guinea were identified and FRONTIERS provided a research assistant for assisting in coordinating the study. FRONTIERS will review the draft report when the study is finished.

\section{CONCLUSION}

This project has revealed that there is clearly a need for technical assistance concerning FGC activities in Guinea. Guinea has a very high prevalence of FGC, but there are very few interventions being implemented to counter the practice. Moreover, most interventions implemented to date have had limited effect on reducing the prevalence of FGC. In addition CPTAFE has maintained the mandate of supporting the Inter-African Committee's strategies for FGC abandonment, which has led to it being rather inflexible in its approach to programming activities.

Several stakeholders in Guinea recognized and appreciated FRONTIERS expertise in this area and requested additional TA; unfortunately, a lack of funding has prevented FRONTIERS from being able to continue providing this assistance. Moreover, several planned activities were not conducted because of the slow pace of implementation by the ministries of Health and Social Affairs, key personnel changes, insufficient attention to implementation and lack of collaboration between key actors (e.g. training in monitoring and evaluation; evaluation of the MOH's WHOsupported FGC medicalization project). It is hoped that funding to enable the Population Council to continue to support partners in Guinea to strengthen their efforts to encourage abandonment of FGC can be found in the near future. 